\title{
ARTIGO
}

DOI: https://doi.org/10.22481/praxis.v14i29.4103

\section{LEITURA E ESCRITA NA PERSPECTIVA DE PROFESSORAS PRÉ-ESCOLARES NA AMAZÔNIA PARAENSE}

\author{
READING AND WRITING IN THE PERSPECTIVE OF PRE-SCHOOL TEACHERS IN \\ THE AMAZONIA PARAENSE
}

\section{LECTURA Y ESCRITA EN LA PERSPECTIVA DE PROFESORAS PRE-ESCOLARES EN LA AMAZONIA PARAENSE}

Sinara Almeida da Costa Universidade Federal do Oeste do Pará - Brasil

Rosianne de Sousa Valente Universidade Federal do Oeste do Pará - Brasil

Hanna Helen da Silva Rêgo

Universidade Federal do Oeste do Pará - Brasil

\begin{abstract}
Resumo: Esta pesquisa, pautada nos pressupostos da Teoria Histórico Cultural de Vigotski está vinculada ao estudo "Os Sentidos de Escrita Atribuídos por Crianças Pré-Escolares", desenvolvida no âmbito do Mestrado Acadêmico em Educação da Universidade Federal do Oeste do Pará - UFOPA. A metodologia consta de observações da prática docente e realização de entrevistas semiestruturadas com duas professoras de pré-escola, sendo uma da rede pública e outra da rede particular de ensino do município de Santarém, PA. Trata-se de uma pesquisa qualitativa com o objetivo de analisar as concepções das professoras da educação infantil acerca da leitura e escrita na pré-escola. A análise do trabalho permitiu observar o contraste quanto aos procedimentos metodológicos desenvolvidos no âmbito da leitura e escrita. Os resultados obtidos demostram que, ainda que haja diferenças significativas quanto ao proceder metodológico das duas professoras para a vivência das crianças com a cultura escrita, ambas se assemelham quando trazem a escolarização precoce para a rotina de atividades, promovendo um regresso quanto às conquistas advindas de estudos no que concerne às práticas de leitura e escrita na educação infantil. A formação das docentes implica diretamente em suas práticas, sendo norteadora para o seu planejamento, mediação e concepção de ensino.
\end{abstract}

Palavras-chave: Leitura e escrita. Pré-escola. Professor.

\begin{abstract}
This research, based on the assumptions of the Cultural Historical Theory of Vygotsky is linked to the study "The Senses of Writing Attributed by Pre-School Children", developed within the scope of the Academic Master in Education of the Federal University of the West of Pará - UFOPA. The methodology consists of observations of the teaching practice and semi-structured interviews with two pre-school teachers, one from the public network and another from the private teaching network
\end{abstract}


of the municipality of Santarém, PA. This is a qualitative research with the objective of analyzing the conceptions of pre-school teachers about pre-school reading and writing. The analysis of the work allowed to observe the contrast regarding the methodological procedures developed in the field of reading and writing. The results show that, although there are significant differences regarding the methodological approach of the two teachers to the children's experience with the written culture, both are similar when they bring pre-school to the routine of activities, promoting a return on the achievements of studies on reading and writing practices in early childhood education. The training of teachers implies directly in their practices, and is guiding for their planning, mediation and teaching conception.

Keywords: Reading and writing. Pre-school. Teacher.

Resumen: Esta investigación, pautada en los presupuestos de la Teoría Histórico Cultural de Vigotski está vinculada al estudio "Los Sentidos de Escritura Atribuidos por Niños preescolares", desarrollada en el ámbito del Máster Académico en Educación de la Universidad Federal del Oeste de Pará UFOPA. La metodología consta de observaciones de la práctica docente y realización de entrevistas semiestructuradas con dos profesoras de preescolar, siendo una de la red pública y otra de la red particular de enseñanza del municipio de Santarém, PA. Se trata de una investigación cualitativa con el objetivo de analizar las concepciones de las profesoras de la educación infantil acerca de la lectura y escritura en la preescolar. El análisis del trabajo permitió observar el contraste en cuanto a los procedimientos metodológicos desarrollados en el ámbito de la lectura y la escritura. Los resultados obtenidos demuestran que, aunque haya diferencias significativas en cuanto al proceder metodológico de las dos profesoras para la vivencia de los niños con la cultura escrita, ambas se asemejan cuando traen la escolarización precoz para la rutina de actividades, promoviendo un retorno en cuanto a las conquistas surgidas estudios en lo que concierne a las prácticas de lectura y escritura en la educación infantil. La formación de las docentes implica directamente en sus prácticas, siendo orientadora para su planificación, mediación y concepción de enseñanza.

Palabras clave: Lectura y escritura. Preescolar. Maestro.

\section{Introdução}

Estudos realizados por Vigotski (1995) e Luria (1988) mostram que as crianças são capazes de aprender linguagem escrita desde pequenas, no entanto, isso não significa que devemos antecipar práticas do ensino fundamental, muitas vezes impróprias até mesmo para essa etapa, pautadas no conhecimento mecanizado das técnicas de ler, escrever e contar; desconsiderando as relações entre os conhecimentos científicos e o contexto social e cultural no qual a criança vive.

Diante do cenário atual em que se desenham essas práticas, especialmente com as crianças pré-escolares, Mello (2009, p. 23) diz que "muito do que temos feito com a educação das nossas crianças pequenas na escola da infância e mesmo no ensino fundamental, especialmente no que concerne à aquisição da escrita, carece de uma base científica" e que, diante dos novos conhecimentos que temos hoje, "podemos buscar, com base nesses novos 
conhecimentos, maneiras de melhorar a forma como trabalhamos para garantir aquilo que todos queremos e que é a maior conquista que a educação pode permitir: a formação máxima das qualidades humanas nas crianças".

Nessa perspectiva, conhecer as condições adequadas para a aprendizagem da criança “é condição necessária - ainda que não suficiente - para a organização intencional das condições materiais de vida e educação que permitam a apropriação das máximas qualidades humanas por cada criança na educação infantil” (MELLO, 2007, p. 88). Daí a importância de conhecer a forma como a criança aprende e tem acesso aos bens culturais mais elaborados da nossa cultura - dentre eles a cultura escrita.

Isso envolve, segundo a autora, a formação dos professores e professoras da infância como "intelectuais capazes" de, ao compreender o papel essencial do processo educativo no processo de humanização, buscar compreender o processo de aprendizagem para organizar vivências na educação infantil que sejam intencionalmente provocadoras da aprendizagem e do desenvolvimento das crianças pequenas (MELLO, 2007, p. 89).

Mas este ainda é um dos grandes problemas hoje, em larga escala. Há professores e professoras da educação infantil que sequer têm formação mínima para atuar nessa etapa educacional. "Tais profissionais são apenas contratados por curto período de tempo, sem a exigência de formação superior adequada" (VALENTE; COSTA, 2017, p. 83).

Essa realidade é preocupante, pois as crianças ficam à mercê de uma educação precária sem vistas ao desenvolvimento (VALENTE; COSTA, 2017). Portanto, vemos que há necessidade de mudança (e com urgência!) no que diz respeito à superação de práticas tradicionais e equivocadas envolvendo o trabalho pedagógico na educação infantil, dentre eles o trabalho com a leitura e a escrita.

Qual seria, então, a peculiaridade do trabalho com a leitura e a escrita na educação infantil? Esta preocupação não é recente. Vygotsky (1995), em 1930, ao escrever sobre a préhistória da linguagem escrita, sobre o percurso de apropriação da escrita pela criança, discute o papel fundamental que essa ferramenta desempenha no desenvolvimento cultural infantil e chama a atenção para o lugar restrito que ela vinha ocupando nas práticas escolares, pela ênfase dada à mecânica de ler que acabava obscurecendo a linguagem escrita.

Nesse sentido, o papel do professor, como pessoa mais experiente, é organizar de forma adequada as condições de vida e educação das crianças no mundo da cultura, inclusive da cultura escrita (VIGOTSKI, 1995). Essa organização deve possibilitar experiências em que "as crianças se expressem por múltiplas linguagens como o desenho, a pintura, a brincadeira 
de faz-de-conta, a modelagem, a construção, a dança, a poesia e a própria fala" (MELLO, 2010a, p. 51). Para a autora, convivendo dessa forma com a escrita utilizada em sua função social, a necessidade da escrita vai se instalando na criança.

Tendo em vista o papel da linguagem escrita no desenvolvimento da criança e o papel do professor e da professora no processo de apropriação dessa linguagem por ela, a presente pesquisa teve como objetivo analisar as concepções de professoras de educação infantil acerca da leitura e escrita na pré-escola.

Para o desenvolvimento da pesquisa fez-se necessário o estudo bibliográfico sobre as implicações pedagógicas da Teoria Histórico-Cultural (THC) acerca da leitura e da escrita e uma pesquisa de campo que buscou elementos de reflexão sobre o trabalho de professoras das redes pública e particular. Assim, a pesquisa foi desenvolvida durante o ano letivo de 2017 em duas turmas de educação infantil de duas instituições, sendo uma da rede pública municipal e outra da rede privada de ensino, ambas de Santarém, PA.

A escolha das instituições, das professoras e suas respectivas turmas, justificam-se pelo vínculo da presente pesquisa com a do mestrado citada anteriormente. Sendo assim, o lócus de pesquisa e os sujeitos são os mesmos da pesquisa mencionada. Ambas as professoras têm grande experiência de trabalho na educação infantil, uma média de 20 anos, com formação exigida pela atual LDB (Lei, $n^{\circ}$ 9.396/96).

Como instrumento para produção dos dados optou-se pela observação e a entrevista semiestruturada que, segundo Lüdke e André (1986), representam instrumentos básicos para se obter informações dentro de uma abordagem qualitativa, na qual se inscreve esta pesquisa. Como forma de registro foram utilizadas fotografia, gravação de áudio e diário de campo. Foram 4 dias de observação em cada sala, no turno matutino.

Ao final das observações foi realizada a entrevista com as professoras. As perguntas nela contidas tratavam da experiência no âmbito da educação, importância e concepção sobre linguagem escrita, desenvolvimento de projetos de leitura, relação teoria-prática e avaliação de suas metodologias sobre leitura e escrita para com as crianças.

\section{A leitura e a escrita na educação infantil: ênfase no trabalho pedagógico do professor}

A leitura e a escrita são instrumentos importantes para a vivência em sociedade e cada sujeito deve, ou pelo menos deveria, ter acesso a elas de forma efetiva desde a sua infância. Nessa perspectiva, Vigotski (1995) afirma que a apropriação da leitura e da escrita é 
fundamental para o desenvolvimento cultural da criança, pois ler e escrever são ações essenciais para a inserção delas nas situações de interação em uma sociedade letrada.

Para Leontiev (2004) é no processo de apropriação que o sujeito aprende e se desenvolve historicamente, num dado contexto cultural, dentro das condições de vida e de educação de que participa e nas relações que estabelece com o outro, porque se constitui nessa relação. Assim, a leitura e a escrita nascem do desejo de expressão criado na criança pelas condições de vida e de educação das quais participa (LEONTIEV, 2004).

Mello (2007) entende que, desde a educação infantil, a criança deve ser inserida na cultura escrita em sua forma mais elaborada, para que possa reconhecer a funcionalidade do uso social da escrita. E isso não se refere a textos prontos sem nenhum significado, mas à oportunidade de vivência da escrita, seja para escrever um lembrete, deixar um aviso na geladeira, registrar um pensamento, etc. Desse modo, a criança irá conhecer a função social que a leitura e a escrita exercem no contexto social e cultural em que vive (MELLO, 2010).

Com o reconhecimento da função social, a criança passa a necessitar da escrita (VIGOTSKI, 1995). Nesse sentido, Mello (2010a, p. 46) ressalta que "convivendo dessa forma com a escrita utilizada em sua função social, a necessidade da escrita vai se instalando na criança". Este desejo de saber escrever e ler irá acontecer de forma natural (VIGOTSKI, 1995), sem a pressa do professor em apresentar o alfabeto e fazer com que a turma o decore ou mesmo faça com que as crianças aprendam penas a grafar letras.

Para Mello (2009) essas tarefas que são tão comuns nas salas de educação infantil não trazem nenhuma influência positiva para o aprendizado da criança, ao contrário, podem trazer sérias consequências quanto à compreensão do que se lê e escreve. Segundo a autora, há uma concepção muito forte, muitas vezes sustentada pela pressão dos pais, mas, sobretudo, pela própria formação dos professores que trabalham na educação infantil - que defende a antecipação da escolarização (MELLO, 2009, p. 24).

Essa concepção se deve, em parte, ao desconhecimento dessas atividades próprias da infância, como as brincadeiras, o desenho, a construção, a modelagem, a poesia e a própria fala da criança, pois tais atividades são vistas como improdutivas, afirma a autora. No entanto, são essas atividades que promovem o desenvolvimento infantil, em especial a brincadeira de faz-de-conta. Todas elas, quando trabalhadas de forma significativa, contribuem para a inserção da criança na cultura escrita (VIGOTSKI, 1995).

Nesse caso, Vigotski (1995) afirma que é necessário utilizar a escrita considerando o fim social para o qual foi criada - para escrever ou registrar vivências, expressar sentimentos e 
emoções, comunicar-se. E é a partir das condições de vivência adequadas apresentadas pela professora e pelo professor que "vão sendo formadas as qualidades humanas, necessárias à apropriação da escrita, como o pensamento, a linguagem, o autocontrole da conduta, a função simbólica da consciência”, etc. (MELLO, 2010, p. 337). Essas funções:

[...] se formam justamente ao longo da idade pré-escolar por meio do brincar e das demais atividades de expressão como o desenho, a pintura, a modelagem. Não tendo essas funções formadas, é maior o esforço que o professor e as crianças têm que fazer para a execução das tarefas de escrita. (MELLO, 2010, p. 337).

Para que a professora e o professor compreendam isso e possam desenvolver práticas que apresentem a escrita de forma a contemplar suas funções sociais, a formação é essencial, lembrando que, segundo Mello e Lugle (2014), toda prática pedagógica deve estar alicerçada em uma teoria que dê base científica para responder as questões: "Para que serve a educação? Como as crianças aprendem?". Desse modo, a THC visa o desenvolvimento da criança em suas potencialidades e vê a escola como promotora de desenvolvimento.

O referido arcabouço teórico parte do pressuposto de que o ser humano é um ser de natureza social, o que significa dizer que suas qualidades humanas - as capacidades, habilidades e aptidões, ou, em outras palavras, sua inteligência e personalidade - são aprendidas (LEONTIEV, 2004). Mas, para que haja esse aprendizado, as crianças devem ser apresentadas às mais variadas formas de cultura, e o professor deve organizar o ambiente educativo de modo a possibilitar com que isso aconteça. Assim, os estudos feitos por Vigotsky (1995) e seus colaboradores indicam que a essência do processo de desenvolvimento é a apropriação da experiência acumulada historicamente, pois a fonte das qualidades humanas é a cultura.

Segundo o autor, para ser humano, o sujeito apropria-se da cultura humana que é criada em meio a condições que propiciem a humanização; em contato com as características peculiares do ser humano, o desenvolvimento vai se tornando parte de si, de forma a transformar o mundo ao seu redor e, também, ser transformado. (LEONTIEV, 2004; VIGOTSKI, 1995).

É nesse sentido que para THC, o desenvolvimento é resultado da aprendizagem, e não o contrário como se pensava antes. A criança precisa ter contato com os objetos da cultura em sua forma diversificada, implicando em novas aprendizagens e, na escola, o professor deve possibilitar diferentes formas de apresentação da cultura para a criança. 
Falando diretamente no âmbito escolar, se a cultura for limitada às crianças, há um grave retrocesso para elas, que deixam de conhecer formas variadas de culturas, e se veem presas à mesma rotina, aos mesmos livros, aos mesmos materiais na sala de atividades, causando um desenvolvimento lento, enquanto poderiam contemplar em seu meio escolar, a diversidade existente em tantas coisas e aprender uns com os outros (ANDRADE, 2002; 2007; COSTA, 2011; SALES, 2007; SCHRAMM, 2009).

Nesse processo de formação da criança, a professora e o professor da educação infantil tem um papel fundamental, pois são eles os organizadores do ambiente educativo para que a aprendizagem ocorra, incluindo-se aí, a leitura e da escrita. E é razoável supor que tal papel está estreitamente relacionado à formação adequada e ao compromisso com a profissão. Quando a formação do professor é precária, certamente as chances de as crianças terem uma educação humanizadora, que objetive seu desenvolvimento integral, são menores.

Portanto, o professor, nesse processo, deve está atento para possibilitar oportunidades para a ampliação do universo cultural das crianças, não somente ensinando, mas dando vez e voz para elas, estabelecendo uma relação de colaboração entre educador e educando, não a limitando, muito pelo contrário, dando liberdade para estar sempre contando com seu auxílio. (MELLO; LUGLE, 2014).

\section{Resultados}

Inicialmente apresenta-se a prática observada, considerando a formação das professoras, a organização do espaço concernente aos materiais da cultura escrita e as atividades propostas às crianças. Em seguida, destacam-se as concepções de linguagem escrita das duas professoras.

\subsection{As instituições- lócus da pesquisa ${ }^{1}$}

Para Mello (2007, p.85) a creche e a escola da infância podem e devem ser os melhores lugares para a educação das crianças pequenas. Esta afirmação nos leva a pensar que as instituições de educação infantil tem o dever de organizar as condições adequadas de educação para a aprendizagem e desenvolvimento da criança.

\footnotetext{
${ }^{1} \mathrm{O}$ nome da instituição descrito nos pontos 3.1 e 3.2, bem como os nomes das professoras participantes da pesquisa foram substituídos por nomes fictícios para preservar seus anonimatos.
} 
A instituição pública de educação infantil denominada aqui de Instituição Esperança está localizada em um bairro periférico da cidade e funciona atualmente em um prédio alugado pela Secretaria Municipal de Educação (SEMED). A instituição atende 260 crianças de 03, 04 e 05 anos, em tempo parcial e integral, sendo distribuídas em 13 turmas, contendo aproximadamente 20 crianças em cada sala e um professor para cada turma.

Pelo fato de não ser um prédio construído com a finalidade de abrigar uma instituição de ensino, as salas de atividades são muito pequenas, dificultando até a locomoção da professora e das crianças. Possui central de ar, porém a sensação é de ambiente abafado e com pouca iluminação. Quanto à organização da sala, há o alfabeto em uma enorme centopeia que se encontra na parede acima do quadro negro, e na parede ao fundo há desenhos da Turma da Mônica. Os materiais de leitura e escrita se resumem a isso. Não há livros de literatura, painéis de chamada, calendário ou outros materiais que poderiam ser utilizados na apresentação da escrita às crianças.

A instituição particular denominada de Novo Horizonte está localizada em um bairro não periférico; o setor de educação infantil está localizado dentro do campus da universidade a que tem vínculo e pode usufruir de toda a sua infraestrutura. Possui uma ampla área na qual são distribuídas: 08 salas de atividades, cada uma com equipamentos e mobílias adequados a faixa etária das crianças. Além de toda estrutura física, a instituição conta com vários materiais pedagógicos e tecnológicos com o intuito de oferecer melhores recursos para professores e alunos durante todo o processo de ensino-aprendizagem.

A turma investigada é intitulada como "Infantil 5" pela instituição (5 a 6 anos). Nessa fase, segundo o documento, a instituição visa o desenvolvimento integral da criança nos aspectos biológicos, psicológicos e cognitivos. Enfatiza a coordenação motora escrita, a continuidade do processo de alfabetização da criança através da construção da língua escrita a partir de um processo de letramento, bem como o desenvolvimento do raciocínio lógico matemático e o domínio das quantidades numéricas.

As salas de atividades são amplas. Cada sala tem seu próprio bebedouro e banheiro, dando um conforto às crianças. A sala pesquisada contempla também itens como televisão, aparelho de DVD e espelho. Há uma estante com livros diversos, um baú com livros do gênero quadrinhos e histórias curtas, um portador de textos e muitos brinquedos.

O parquinho está localizado no corredor que dá acesso às salas. O momento de brincadeira nesse espaço é muito esperado pelas crianças, porém é também o momento em 
que a professora tira um tempo para conversar com outras professoras, deixando a tarefa de "vigiar" as crianças somente para a estagiária da sala.

\subsubsection{Professoras: sujeitos da pesquisa}

A professora Mariza (seguimento público) tem 60 anos, é formada no magistério e em 2015 concluiu Pedagogia no Plano Nacional de Formação de Professores - Parfor, na Ufopa, tem graduação em Ciências Sociais pela Universidade Luterana do Brasil (Ulbra), formação a partir da qual trabalhou no ensino médio. Além de trabalhar no turno matutino na Escola Municipal de Educação Infantil (EMEI), a professora Marisa tem outro trabalho no contraturno.

Em algumas observações, foi possível perceber que a professora gosta de fazer brincadeiras com as crianças e também participa junto com elas. Em determinada observação, enquanto professora e crianças esperavam a chegada da professora de dança para o ensaio da festa junina, Marisa, vendo que algumas crianças estavam debaixo da mesa se escondendo umas das outras, propôs a brincadeira de esconde-esconde. Como não tinha planejado outra atividade caso a professora de dança não viesse, a brincadeira de esconde-esconde foi visivelmente uma forma de a professora "controlar" as crianças, mas estas se divertiam ao verem sua professora brincando junto com elas.

A professora também demonstrava conhecer bem as crianças. No momento de chegada e saída ela sempre buscava conversar com os pais caso algo de anormal tivesse acontecido com seu filho. O vínculo com as crianças é tão estreito que elas se sentem à vontade para contar coisas particulares referentes às suas famílias, o que facilita à professora perceber quando alguma criança apresenta comportamento diferente ao que está habituado. Por exemplo, em determinado dia de observação uma criança demonstrou muita sensibilidade durante a manhã, estava chorosa e a professora relatou à pesquisadora que esta criança tinha lhe contado que seus pais haviam se separado, e que essa situação refletia a sensibilidade a qual a criança estava passando.

A professora Inês possui formação fora do estado, no Paraná, onde se formou em Pedagogia em 2002, e fez pós-graduação em Educação Infantil em 2003, também se graduou em Gestão do Trabalho Pedagógico no Centro Universitário Internacional- Uninter/Santarém, em 2008. Segundo ela, o trabalho que realiza se deve à sua formação ocorrida no Paraná, como diz no seguinte trecho: 
E eu devo a [formação no Paraná], porque desde que eu entrei lá não era esse método, e eles investem muito nos professores lá. Então, assim, todo mês a gente tinha cursos, né, sobre esses métodos diferenciados a partir do brincar, a partir de jogos, a partir de histórias, né, que ia desenvolvendo a leitura e a escrita de uma forma bem tranquila, né, lúdica e bem prazerosa pra criança.

Ela é professora há vinte e cinco anos e desse total de tempo de trabalho na educação só teve experiência em escola pública durante dois anos quando ainda estava no estado do Paraná. Ao vir para o Pará, disse que se surpreendeu com a metodologia da família silábica, algo defasado, mas que ainda vigora fortemente na região.

A professora Inês foi a criadora de um projeto de leitura muito interessante, chamado "Viajando com as Histórias", que consiste em cada segunda-feira uma criança apresentar a história do livro que levou para casa na segunda-feira passada. Junto com a família, ela deverá passar aos seus colegas a história do seu livro. O modo de apresentação é variado, pode ser com fantoche, cartazes ou então com a caracterização da criança com algum personagem do livro. Isso demonstra o quanto a professora não habita em uma zona de conforto e se preocupa em trazer às crianças atividades diferenciadas em suas práticas pedagógicas na sala de atividades.

\subsection{A Perspectiva das professoras sobre a leitura e a escrita na pré-escola}

As entrevistas realizadas com as professoras ocorreram ao final das observações, sendo possível perceber aproximações e distanciamentos de suas respostas com as práticas que exerceram durante os dias observados.

Ao se perguntar sobre os objetivos do trabalho com a leitura e a escrita na educação infantil, foram obtivas seguintes respostas:

Na educação infantil não é escolarizar as crianças, vai letrar as crianças. Mas é importante que a criança por meio de conteúdos, por meio de experiências de vida, por meio de historinhas, por meio de várias e várias situações, as crianças elas vão aprendendo a lidar com a leitura e a escrita, o que é muito importante porque quando uma criança vai já para uma $1^{a}$ série ela já não tem tanta dificuldade porque ela já tem um conhecimento bem amplo do que é a leitura e a escrita (Professora Marisa).

Deve ser feita de uma forma tranquila e prazerosa. Porque quando você começa duma cobrança "você tem que saber..." nenhum adulto gosta, imagine uma criança, né. Então eu acho que ela tá numa fase que ela tem que de uma forma, através de uma brincadeira, através do lúdico, né, que seja uma coisa prazerosa pra ela, porque tudo o que é prazeroso você vai aprendendo até sem perceber, né. (Professora Inês). 
Observa-se que, nas palavras da professora Marisa, é possível notar que esta reconhece, em parte, os objetivos da educação infantil, reforçando a ideia de que não se deve "escolarizar" as crianças. Porém é expressamente visível a contradição entre o que diz e sua prática pedagógica. A professora fala a respeito do letramento, mas durante suas práticas envolvendo a leitura e a escrita o que pôde ser observado foi o ensino tradicional através das famílias silábicas, além de excesso de atividades xerografadas, sem significado.

Desse ponto de vista, Mello (2010, p. 336) afirma que "compreender a linguagem escrita como um instrumento cultural complexo implica em rever as formas de apresentação da linguagem escrita para as crianças e almejar a formação de leitores e produtores de texto." Uma das marcas registradas da educação infantil no ensino público (MELLO, 2009, 2010a), e em especial na sala da professora Marisa, é a aparente falta de conhecimento em relação ao trabalho com a leitura e escrita no seu uso social.

Por outro lado, a professora Inês destaca a importância de um trabalho prazeroso com a leitura e escrita, mas apesar de se esforçar nessa direção, durante as observações notouse um excesso de atividades na rotina das crianças dificultando com que se envolvessem por completo nas atividades propostas. Embora haja um cuidadoso planejamento, as atividades constantes podem se tornar um fardo para as crianças, conforme lembra Mello (2010): "Quando se introduz à criança a linguagem escrita iniciando por seu aspecto técnico, outro problema ainda se apresenta: as tarefas da escrita, pela ausência de motivos geradores de sentido, em geral se tornam longas e cansativas tomando o tempo da atividade lúdica" (MELLO, 2010, p. 337).

Nesse sentido, o brincar, atividade-guia do desenvolvimento na idade pré-escolar (LEONTIEV, 2004, VIGOTSKI, 2016) quase não foi visto durante as observações, salvo a sexta-feira, onde as crianças podem levar brinquedos de casa para compartilhar com seus colegas. A aquisição da leitura e escrita é importante, mas na educação infantil ao invés de trabalhar a técnica, deve-se priorizar o contexto no qual tais práticas são desenvolvidas, criando na criança a necessidade e o desejo de conhecê-las e utilizá-las.

Ao serem questionadas sobre a pressão em relação à aprendizagem da leitura e escrita na educação infantil, as professoras disseram:

Olha, eu acredito que não seja obrigatório a criança aprender a ler na educação infantil, porque tá se falando de pré-escola, né, de maternal. $\mathrm{Na}$ minha opinião, a criança se ela despertar pra leitura e a escrita, se ela tiver a oportunidade de vivenciar essa leitura e escrita nessa educação infantil, e ela desperte pra leitura e escrita eu acredito que nada venha a ... sabe ... a 
impedir que ela consiga ler. Porque eu como professora de educação infantil há 29 anos... eu já tive crianças que conseguiram ler e escrever na educação infantil. (Professora Marisa)

Eu acho que a gente não deve cobrar isso da criança, eu acho que a gente deve deixar ... a gente deve estimular, incentivar, através de brincadeiras, de jogos, do faz-de-conta, do desenho, do livro de histórias. Mas aí você tem que deixar uma coisa mais livre pra criança, entendeu? De acordo com o interesse dela. Aí é claro que vem criança que estimulada desde casa, então ela mesmo te cobra, às vezes, um pouco mais. E eu acho que você tem que respeitar o limite de cada um, né, o desenvolvimento de cada uma e procurar sempre estar estimulando pra que elas se desenvolvam cada vez mais nesse aprendizado. (Professora Inês).

Durante a entrevista com a professora Marisa, o termo "despertar" foi utilizado diversas vezes. Entende-se, nesse caso, que o despertar seja o desabrochar de uma ação que ela já tenha e que precisa apenas ser acompanhada sem que haja, necessariamente, uma intenção pedagógica no sentido de criar a necessidade de ler e escrever na criança. As atividades sem significado não fazem com que as crianças sintam essa necessidade.

Segundo Mello (2015), convivendo com a escrita usada em sua função social, a necessidade de escrever vai se instalando na criança. Não é preciso pressionar ou querer adiantar esse processo. Se a escrita for apresentada adequadamente, a aprendizagem será natural e prazerosa.

Quanto à professora Inês, apesar de falar sobre respeitar o limite de cada criança, durante as observações foi possível perceber a pressão para que crianças que ainda não sabiam ler também terminassem suas atividades. Um dos motivos para essa pressão pode ser a cobrança dos pais que, percebendo que o filho teve um baixo desempenho podem culpabilizar a professora.

É importante enfatizar a ideia de que o bom desempenho escolar é uma exigência cada vez mais presente na sociedade atual, tornando-se condição sine qua non para o sucesso profissional de qualquer indivíduo. A forma impositiva com que essa exigência se manifesta, seja na escola, na família ou em outros ambientes sociais, muitas vezes prejudica o desenvolvimento integral das crianças, já que se concentra, quase sempre, no aspecto cognitivo. É compreensível, portanto, o fato de que as escolas, os pais e as professoras, não alheios a essa realidade, a levem em consideração. Infelizmente, a exigência por um suposto "sucesso escolar" das crianças, além de expressar uma concepção que, em termos legais, já foi superada, parece contribuir para sua manutenção. 
Ao serem questionadas sobre algum projeto de leitura desenvolvido por elas na escola, as docentes disseram:

$\mathrm{Na}$ escola não existe nenhum tipo de projeto de leitura e de escrita pras crianças da educação infantil não. A gente tem os projetos que são da instituição, da escola, né, mas que não estão assim ... sobre essa questão de leitura e da escrita. A gente cria situações, né. (Professora Marisa).

Na educação infantil esse projeto de leitura é a turma do Infantil 5. É um projeto que se chama Viajando com as histórias. Então toda semana um aluno leva uma maleta, que ele vai até a biblioteca e escolhe a história da preferência e na próxima segunda ele retorna, porque junto com a família ele prepara a história, aí vai da criatividade de cada família. (Professora Inês).

O Projeto Político Pedagógico da EMEI não contempla um projeto de leitura e, também, não foi visto por parte da professora um interesse quanto a isso, afinal, se não há um projeto matriz da instituição, ela poderia pensar em algum para a sua turma, caso considerasse importante.

O projeto criado pela própria professora Inês objetiva a ação de envolver diretamente as crianças com a leitura, além de fazer a ponte entre os pais e as crianças, pois os pais são os responsáveis por preparar a criança para que, quando esta retorne no prazo de uma semana, possa recontar aos colegas a história com a qual passou sete dias. A apresentação pode ser em forma de poesia, peça teatral, fantoches etc. $\mathrm{O}$ objetivo principal é que a criança possa estar em contato direto com a leitura. Esse tipo de projeto é interessante e ousado, o que, segundo Mello (2015), é fundamental para apreendermos novas formas de relação com a cultura.

Quanto aos métodos e estratégias de inserção da leitura e escrita na educação infantil, as professoras responderam:

Há várias estratégias que você trabalha a questão da leitura e escrita. Você lidando com jogos, você lidando com a ludicidade, você lidando com brincadeiras, envolvendo a questão do letramento, a questão da leitura ... Eu como professora da educação infantil tive muita história como ferramenta pra despertar a leitura e a escrita na educação infantil. Eu tive muito essa ferramenta como contação de história, porque desperta a vontade dele ler, tá entendendo? Então eu trabalho muito essa questão da história, de usar o próprio nome das crianças, entendeu? Daí eu começo a trabalhar a questão da leitura e da escrita. (Professora Marisa).

$\mathrm{Na}$ verdade, eu sou do Sul, né. Quando eu vim pra cá eu fiquei bem assustada quando eu comecei a visitar as escolas e ver as famílias silábicas, porque eu já vim de lá com outra visão. Na verdade... eu acho que essa questão de família silábica eu peguei só os dois primeiros anos que eu trabalhei no município, só que no segundo ano que eu comecei a trabalhar, já 
começou propostas diferentes, a gente já fazia curso e já não existia mais, então praticamente na minha vida profissional eu não trabalhei. Na verdade quando criança eu aprendi assim né, mas graças a Deus que eu ensinei na família silábica foi uma coisa muito rara assim e já por eu não gostar, não é não gostar do método, é por achar que é um método que não se encaixa né, uma coisa mecânica, uma coisa muito decoreba digamos assim, né. (Professora Inês).

A professora Marisa novamente menciona experiências pedagógicas que no período da observação não foram presenciadas em sua prática com as crianças. Um ponto importante quanto a isso foi a ausência do planejamento de suas atividades, o que prejudica a qualidade de ensino pela qual as crianças estão sujeitas. Diversas vezes a professora saía de sala para que pudesse tirar cópias das atividades, o que induz a ideia de que não houve uma organização prévia de sua parte.

A professora Inês se deteve em falar a respeito da família silábica. Tal método tradicional é algo comum entre as instituições públicas de Santarém, o que causou estranhamento por parte da professora que é oriunda de outro Estado. Todavia, seu modo de trabalho também envolve a relação letra-som.

Quanto a isso, Mello (2015) ressalta:

Ainda que tenha as melhores intenções de ensinar a leitura e a escrita para a criança, ao enfatizar a relação som-letra, ou seja, ao apresentar a escrita, começando por seu aspecto técnico, a professora ou o professor da educação infantil dificulta a aprendizagem da leitura e escrita pela criança. (MELLO, 2015, p. 46).

E mais, afirma a autora, "engana-se quem pensa que o domínio da correspondência entre som e letra seja a meta fundamental a ser alcançada no processo de apropriação da escrita". (MELLO, 2015, p. 144).

\section{Considerações finais: reflexões e desafios}

Neste estudo pôde-se perceber que a leitura e a escrita são elementos essenciais para qualquer pessoa em uma sociedade letrada. Desse modo, participar desse mundo letrado e de uma cultura escrita requer o entendimento, principalmente, da sua função social. No entanto, apesar dos estudos no que concerne a essas práticas, em especial com as crianças pequenas, o que ainda se pode observar é o trabalho mecânico caracterizado por uma prática exaustiva de repetições de letras e números. (MELLO, 2010). 
Foi possível observar que as professoras apresentaram estratégias diferenciadas para a vivência das crianças com a cultura escrita. No entanto, na escola pública o tempo de ociosidade era demasiado excessivo e as crianças eram deixadas, a maior parte do tempo, sem nenhuma atividade. Quando as atividades eram propostas, costumavam ser mecânicas, como: copiar do quadro, cobrir letras, pintar desenhos xerografados etc. A professora da instituição pública relatou, em uma de suas conversas informais com a pesquisadora, que ficava feliz quando seus alunos reconheciam uma letra em algum lugar. Isso era, para ela, sinônimo de que seu trabalho em alfabetizar as crianças estava sendo realizado com êxito.

$\mathrm{Na}$ instituição particular, o ritmo acelerado e carregado de atividades parecia sobrecarregar as crianças, limitando suas ações no âmbito do brincar livre e expressar seus sentimentos e pensamentos. Também foi possível perceber que as crianças eram silenciosas, não conversam muito entre si; apenas quando a professora perguntava sobre a formação das palavras, as crianças dialogavam interagindo com ela.

Ainda que não compartilhem das mesmas práticas, as professoras apresentam a escrita às crianças de maneira a resumi-la ao cumprimento de tarefas, pois, enquanto uma trabalha as letras sem nenhuma vinculação com a função social da escrita (explora somente a técnica e não a função), a outra professora trabalha a sonorização das palavras por meio das sílabas. Apesar do esforço da professora da instituição particular para envolver as crianças em atividades de leitura e contação de histórias, o foco é a formação de palavras e não a aprendizagem da escrita como prática cultural, como algo que tenha sentido para a criança.

Portanto, é necessário que os professores e professoras dessa etapa da educação, tão importante para a formação das qualidades humanas nas crianças, tenham conhecimento científico a respeito desse valioso instrumento cultural, pois acredita-se que uma prática pedagógica que proporcione o desenvolvimento de atividades significativas, com base científica, pode contribuir para que elas desenvolvam conhecimentos significativos sobre a linguagem escrita desde a educação infantil. O aprender de forma errada, seja a linguagem escrita ou outros conhecimentos, causa um atraso significativo no desenvolvimento das crianças e afeta seus desempenhos em outras etapas de estudos. O desafio é grande, porém vale o esforço para que as crianças de hoje possam estar livres dos mesmos erros a que fomos submetidos décadas anteriores. 


\section{REFERÊNCIAS}

ANDRADE, Rosemeire Costa de. A espera e a ociosidade na rotina da creche comunitária de Fortaleza. Dissertação (Mestrado) - Faculdade de Educação, Universidade Federal do Ceará, Fortaleza, 2002.

ANDRADE, Rosemeire Costa de. A rotina da pré-escola na perspectiva das professoras, das crianças e de suas famílias. Tese (Doutorado)- Faculdade de Educação, Universidade Federal do Ceará, Fortaleza, 2007.

BRASIL. Ministério da Educação - MEC. Lei de Diretrizes e Bases da Educação Nacional - LDBEN no 9394/96 . Brasília: MEC, 1996.

COSTA, Sinara Almeida da. "NA ILHA DE LIA, NO BARCO DE ROSA": o papel das interações estabelecidas entre a professora de creche e as crianças na constituição do eu infantil. Tese (Doutorado)- Faculdade de Educação, Universidade Federal do Ceará, Fortaleza: 2011.

LEONTIEV, Alexis Nikolaevich. O desenvolvimento do psiquismo. Tradução Rubens Eduardo Frias. $2^{a}$ edição. São Paulo: Centauro, 2004.

LÜDKE, Menga; ANDRÉ, Marli E. D. A. Pesquisa em educação: abordagens qualitativas. São Paulo: EPU, 1986.

LURIA, Alexander Romanovich. O desenvolvimento da escrita na criança. In: VIGOTSKI, Lev Semyonovich.; LURIA, Alexander Romanovich; LEONTIEV, Alexis Nikolaevich. Linguagem, desenvolvimento e aprendizagem. São Paulo: Ícone, 1988, p. 21-37.

MELLO, Suely Amaral. Pressupostos da Teoria Histórico-Cultural para a apropriação da cultura escrita pela criança. Perspectiva, Florianópolis, v. 33, n. 1, jan./abr. 2015.

MELLO, Suely Amaral. Ensinar e Aprender a Linguagem Escrita na Perspectiva HistóricoCultural. Psicologia Política, vol. 10, jul./dez. 2010.

MELLO, Suely Amaral. Contribuições da educação infantil para a formação do leitor e produtor de textos. (Org.) Diretrizes educacionais pedagógicas para educação infantil/Secretaria Municipal de Florianópolis. Florianópolis: Prelo Gráfica \& Editora ltda, 2010a.

MELLO, Suely Amaral. O processo de aquisição da escrita na Educação Infantil: contribuições de Vigotski. In: FARIA, A. L; MELLO, S. A. (Orgs). Linguagens Infantis outras formas de Leitura. $2^{a}$ ed. Campinas, S.P.: Autores Associados, 2009, p. $21-40$.

MELLO, Suely Amaral. Infância e humanização: algumas considerações na perspectiva histórico-cultural. Perspectiva, Florianópolis, v. 25, jan./jun. 2007.

MELLO, Suely Amaral; LUGLE, Andreia Maria Cavaminami. Formação de professores: implicações pedagógicas da Teoria Histórico-Cultural. Revista Contrapontos - Eletrônica, Vol. 14 - n. 2 - mai-ago 2014. 
SALES, Sinara Almeida da Costa. Falou, tá falado: as representações sociais docentes sobre infância, criança, Educação Infantil e papel do professor. Dissertação (Mestrado em Educação) - Faculdade de Educação, Universidade Federal do Ceará, Fortaleza, 2007.

SCHRAMM, Sandra Maria de Oliveira. A construção do eu no contexto da Educação

Infantil: influências da escola e a perspectiva da criança sobre esse processo. Tese

(Doutorado)- Faculdade de Educação, Universidade Federal do Ceará, Fortaleza, 2009.

VALENTE, Rosianne de Sousa; COSTA, Sinara Almeida da. Formação de Professores de Educação Infantil no Pará: apontamentos preliminares. (Orgs). Educação e Realidade Amazônica. Volume 2. Uberlândia: Navegando Publicações, 2017.

VIGOTSKI, Lev Semyonovich. Obras Escolhidas - tomo III. Visor editora: Madri, 1995.

VIGOTSKI, Lev Semyonovich. Aprendizagem e desenvolvimento intelectual na idade escolar. In: VIGOTSKI, Lev Semyonovich.; LURIA, Alexander Romanovich; LEONTIEV, Alexis Nikolaevich. Linguagem, desenvolvimento e aprendizagem. Tradução de Maria da Pena Villas Lobo. 14a edição. São Paulo: Ícone, 2016.

\section{SOBRE AS AUTORAS:}

\section{Sinara Almeida da Costa}

Doutora em Educação, professora do Programa de Pós-Graduação em Educação da Universidade Federal do Oeste do Pará (UFOPA), lotada no Instituto de Ciências da Educação, curso de Pedagogia. Líder do Grupo de Estudos e Pesquisas em Educação Infantil da UFOPA. E-mail: sinaraacs@ hotmail.com

\section{Rosianne de Sousa Valente}

Mestranda em Educação pela Universidade Federal do Oeste do Pará (UFOPA). Pedagoga da Secretaria Municipal de Educação de Almeirim, PA. Membro do Grupo de Estudos e Pesquisas em Educação Infantil da UFOPA. E-mail: rosy_valentt@hotmail.com

\section{Hanna Helen da Silva Rêgo}

Graduanda do curso de Pedagogia da Universidade Federal do oeste do Pará (UFOPA). Membro do Grupo de Estudos e Pesquisas em Educação Infantil da UFOPA. Bolsista FAPESPA. E-mail: hanna.iced@gmail.com 